\title{
Backstepping Controller for a Variable Wind Speed Energy Conversion System Based on a DFIG
}

\author{
Sara Mensou, Ahmed Essadki, Issam Minka, Tamou Nasser, Badr Bououlid Idrissi
}

\begin{abstract}
In this paper we present a contribution for the modeling and control of wind energy conversion system based on a Doubly Fed Induction Generator (DFIG). Since the wind speed is random the system has to produce an optimal electrical power to the Network and ensures important strength and stability. In this work, the Backstepping controller is used to control the generator via two converter witch placed a DC bus capacitor and connected to the grid by a Filter R-L, in order to optimize capture wind energy. All is simulated and presented under MATLAB/Simulink Software to show performance and robustness of the proposed controller.
\end{abstract}

Keywords-Wind turbine, doubly fed induction generator, MPPT control, backstepping controller, power converter.

\section{INTRODUCTION}

$\mathrm{T}$ HE development and exploitation of renewable energies has greatly evolved in recent decades. Among these energy sources, there is wind power, which produces electrical energy from the kinetic energy of the wind. This source of energy has been the subject of several researches in electrical and electromechanical engineering in order to optimize and improve the quality of energy produced. Currently, most recent wind turbines are based on variable speed generators to better exploit the wind resources for different value of wind speed, the most used in wind farms is the DFIG, the stator of the machine is connected directly to the grid while the rotor is connected to the grid via a back-to-back power converter which placed a DC Bus Capacitor (Fig. 1) [1]-[3], this structure has many advantages, allows a variable speed operation around asynchronous machine. The power converters used are sized to pass a fraction of the total power of the system, which allows the reduction of losses in power electronics components [4][6].

The aim of this study is to control the whole system by the nonlinear Backstepping approach associate to Lypunov function in order to ensure stability system and maximize the power extracted from the generator-DFIG against variablespeed large wind. To control the rotor side converter (RSC), the voltages references are obtained by the rotor currents control loop, this control loop gets its reference from the Maximum power point tracking algorithm used to maximize

Sara Mensou is with the Electrical Engineering Department of ENSET, Mohammed V University, Rabat, Morocco (corresponding author, e-mail: sara.mensou11@gmail.com).

Ahmed Essadki and Issam Minka are with the Electrical Engineering Department of ENSET, Mohammed V University, Rabat, Morocco.

Tamou Nasser is with the Communication Networks Department of ENSIAS, Mohammed V University, Rabat, Morocco.

Badr Bououlid Idrissi is with the Electromechanical Engineering Department of ENSAM, Moulay Ismaïl University, Meknès, Morocco. the power generated from the wind. As for the grid side converter (GSC), its voltages references are provided from the filter currents control loop, the performance and robustness of this controller are tested in terms of reference tracking and analyzed by simulation results in MATLAB/SIMULINK environment.

This article is organized as follows, in Section I a brief introduction, the modeling of the wind turbine energy and the principle of maximum power point tracking (MPPT) are presented in Section II. In Section III we describe the mathematical development of the Backstepping controller used in the control of the generator, thereafter we present the simulation results and their interpretations, and then we finish by a conclusion.

\section{Modelling OF THE Wind TURBINE ENERGy SySTEM}

\section{A. Modelling of the Wind Turbine}

Wind turbines transform the kinetic energy of the wind to the electrical energy. The aerodynamic power $P_{a e r}$ available on the rotor depends on the power coefficient $C_{p}$ is written as [4]-[7]:

$$
P_{a e r}=C_{p}(\lambda \cdot \beta) \cdot \frac{\rho \cdot S \cdot v^{3}}{2}
$$

where: $\rho$ : Air density ( $\rho=1.22 \mathrm{~kg} / \mathrm{m} 3), S$ : Circular surface swept by the turbine, $v$ : Wind speed, $C_{p}$ : Power coefficient, $\lambda$ : Tip Speed Ratio (TSR), $\beta$ : Pitch angle of the blade.

The TSR $\lambda$ is defined as:

$$
\lambda=\frac{R \cdot \Omega_{t}}{v}
$$

The expression $C_{p}(\lambda . \beta)$ defines the aerodynamic efficiency of the wind turbine it can be expressed as follows [5]:

$$
\begin{gathered}
C_{p}(\lambda . \beta)=0.5176\left(\frac{116}{\lambda_{i}}-0.4 \beta-5\right) e^{-\frac{21}{\lambda_{i}}}+0.0068 \lambda \\
\lambda_{i}=\frac{1}{\lambda+0.008 . \beta}-\frac{0.035}{\beta^{3}+1}
\end{gathered}
$$




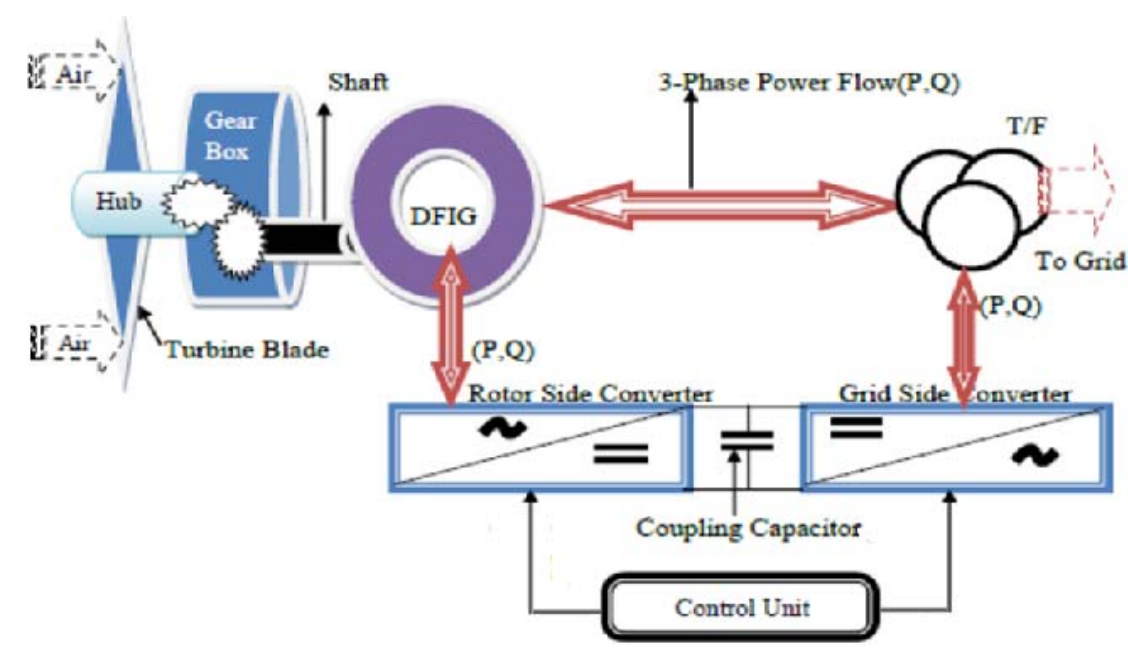

Fig. 1 Wind Energy Conversion System

The characteristics of Aerodynamic power Coefficient $C_{p}(\lambda . \beta)$ depending of $\lambda$ for different values of $\beta$ is presented in the Fig. 2.

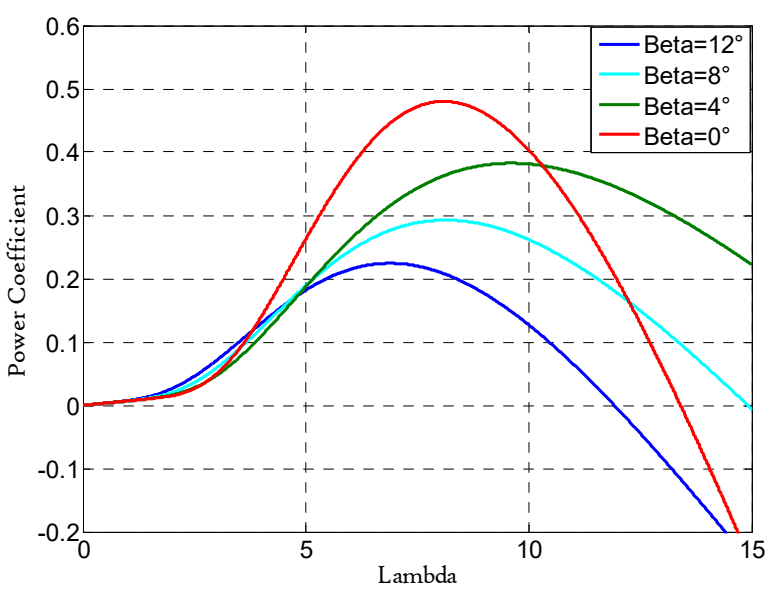

Fig. 2 The characteristics of $C_{p}(\lambda . \beta)$ depending of $\lambda$ for different values of $\beta$

The fundamental equation of dynamics makes it possible to determine the evolution of the mechanical speed from the total mechanical torque applied to the rotor [4]:

$$
J \frac{d \Omega_{m e c}}{d t}=T_{m e c}=T_{g}-T_{e m}-C_{f} \Omega_{m e c}
$$

where: $J$ : The Total inertia, $\Omega_{m e c}$ : The Mechanical speed, $T_{g}$ : The generator torque, $T_{e m}$ : The electromagnetic torque, $C_{f} . \Omega_{\text {mec }}$ : The torque of viscous friction.

\section{B. Extraction of Maximum Power (MPPT Control)}

The aim of this control is to optimize the capture wind energy by tracking the optimal speed, to extract the maximum of the power produced from the wind turbine; we must always adjust the mechanical speed of the DFIG to the wind speed [8].
By setting $\beta$ and $\lambda$ respectively to their optimal values which corresponds to the maximum power coefficient $C_{p \max }$ the wind turbine system will produce optimum electrical power [4]. According to (2) it can be possible to deduce in real time the estimate value of the wind speed:

$$
v_{e s t}=\frac{R \cdot \Omega_{t}}{\lambda_{o p t}}
$$

The electromagnetic torque extracted from the MPPT Control should be applied to the DFIG in order to run the generator at its optimal speed [8]. The expression of the reference electromagnetic torque as a function of the mechanical rotor speed is expressed as [9]:

$$
T_{\text {em ref }}=\frac{1}{2} C_{p \max }(\lambda \cdot \beta) \cdot \frac{\rho \cdot \pi \cdot R^{5}}{\left(G \cdot \lambda_{\text {opt }}\right)^{3}} \Omega_{\text {mec }}^{2}
$$

\section{Modelling of the DFIG}

In this work, we chose a park reference (d-q) linked to the rotating field. Assuming that the flux stator is oriented along the axis $\mathrm{d}$ of the rotating reference frame and is constant, and the stator resistance $R_{s}$ is neglected for high and medium power [3]. The mathematical model of the DFIG in the Park reference $(d-q)$ is given by the following equations [10], [11]:

$$
\left\{\begin{array}{l}
V_{s d}=R_{s} \cdot I_{s d}+\frac{d \phi_{s d}}{d t}-\phi_{s q} \cdot \omega_{s}=0 \\
V_{s q}=R_{s} \cdot I_{s q}+\frac{d \phi_{s q}}{d t}+\phi_{s d} \cdot \omega_{s}=\phi s . \omega_{s} \\
V_{r d}=R_{r} \cdot I_{r d}+\frac{d \phi_{r d}}{d t}-\phi_{r q} \cdot \omega_{r} \\
V_{r q}=R_{r} \cdot I_{r q}+\frac{d \phi_{r q}}{d t}+\phi_{r d} \cdot \omega_{r}
\end{array}\right.
$$


The stator and rotor flux can be described as:

$$
\left\{\begin{array}{l}
\phi_{s d}=L_{s} \cdot I_{s d}+L_{m} \cdot I_{r d}=\phi_{s} \\
\phi_{s q}=L_{s} \cdot I_{s q}+L_{m} \cdot I_{r q}=0 \\
\phi_{r d}=L_{s} \cdot I_{r d}+L_{m} \cdot I_{s d} \\
\phi_{r q}=L_{r} \cdot I_{r q}+L_{m} \cdot I_{s q}
\end{array}\right.
$$

where $\omega_{s}$ is the pulsation of the currents stator and $\omega_{r}$ is the pulsation of the currents rotor, $\mathrm{p}$ is the number of the pole pairs of the DFIG. $R_{s} ; R_{r}$ are the stator and rotor resistance, $L_{s .} ; L_{r}$ are the cyclic stator and rotor inductance, and $L_{m}$ is the mutual inductance.

The expressions for the active and reactive powers of the stator, and the electromagnetic torque are written as follows [4]-[9]:

$$
\begin{gathered}
P_{s}=-\frac{V_{s} \cdot L_{m}}{L_{s}} \cdot I_{r q} \\
Q_{s}=\frac{V_{s} \cdot \phi s}{L_{s}}-\frac{V_{s} \cdot L_{m}}{L_{s}} \cdot I_{r d} \\
T_{e m}=-\frac{3}{2} \cdot p \cdot \frac{L_{m}}{L_{s}} \cdot \varphi s \cdot I_{r q}
\end{gathered}
$$

\section{Modelling of the Filter $R f-L f$}

The GSC is connected to the Network via a Filter $R_{f} L_{f}$, in a reference Park frame $d-q$ the voltage Vs is oriented along the axis q, this implies $V_{s d}=0$ [3], [4], so the expressions of the mathematical model of the filters is giving by:

$$
\left\{\begin{array}{l}
0=L_{f} \frac{d I_{f d}}{d t}+R_{f} \cdot I_{f d}+I_{f q} \cdot L_{f} \cdot \omega_{s}+V_{f d} \\
V_{s q}=L_{f} \frac{d I_{f q}}{d t}+R_{f} \cdot I_{f q}-I_{f d} \cdot L_{f} \cdot \omega_{s}+V_{f q} \\
P_{f}=V_{s q} \cdot I_{f q} \\
Q_{f}=V_{s q} \cdot I_{f d}
\end{array}\right.
$$

\section{BACKSTEPPING CONTROLLER}

The Backstepping approach is a recursive control design for stabilizing highly nonlinear dynamic systems [12]. The principle of the Backstepping controller approach is the use of a virtual control to decompose a complex nonlinear design problem into various simpler design steps. The stability and performance of the system are achieved by using a Lyapunov function which is used to drive the virtual control [10].

\section{A. Control of the Rotor Side Converter (RSC)}

To extract the maximum power generated it is necessary to provide the adequate and the necessary electromagnetic torque which is used to vary the mechanical speed of the DFIG for different value of wind speed [3]. According to (14) and (15) we deduce that $V_{r d}$ and $V_{r q}$ are the components of the rotor voltages to impose on the machine in order to obtain the desired rotor currents. From (12) we deduce that the rotor current $I_{r q}$ can control the electromagnetic torque:

$$
I_{\text {rq ref }}=-\frac{2}{3} \cdot \frac{L_{s}}{p \cdot L_{m} \cdot \varphi_{s}}
$$

According to (7), the expression of the rotor current reference $I_{\text {rqref }}$ becomes:

$$
I_{\text {rq ref }}=\frac{1}{3} \cdot \frac{L_{s}}{p \cdot L_{m} \cdot \varphi_{s}} \cdot C_{p \max }(\lambda \cdot \beta) \cdot \frac{\rho \cdot \pi \cdot R^{5}}{\left(G \cdot \lambda_{\text {opt }}\right)^{3}} \Omega_{\text {mec }}{ }^{2}
$$

From (11) we deduce that the rotor current $I_{\text {rdref }}$ can control the stator reactive power:

$$
I_{r d r e f}=\frac{\varphi_{s}}{L_{m}}-\frac{L_{s}}{\mathrm{~V}_{s} \cdot L_{m}} \cdot Q_{s}
$$

According to (8) and (9) the model of the system can be written as:

$$
\left\{\begin{array}{l}
\frac{d I_{r d}}{d t}=-b . I_{r d}+\omega_{r} \cdot I_{r q}+a \cdot V_{r d} \\
\frac{d I_{r q}}{d t}=-b . I_{r q}-\omega_{r} \cdot I_{r d}-c . \phi s . \omega_{r}+a \cdot V_{r q}
\end{array}\right.
$$

where:

$$
\left\{\sigma=1-\frac{L_{m}{ }^{2}}{L_{s} \cdot L_{r}} ; a=1-\frac{1}{\sigma \cdot L_{r}} ; b=a \cdot R_{r} ; c=a \cdot \frac{L_{m}}{L_{s}}\right.
$$

The currents rotor tracking errors $e_{2}$ and $e_{3}$ are defined by:

$$
\left\{\begin{array}{l}
e_{1}=I_{r d r e f}-I_{r d} \\
e_{2}=I_{r q r e f}-I_{r q}
\end{array}\right.
$$

The derivative of equation errors variables gives:

$$
\left\{\begin{array}{l}
\dot{e_{1}}=I_{r d r e f}-\dot{I_{r d}} \\
\dot{e_{2}}=I_{r q r e f}-\dot{I}_{r q}
\end{array}\right.
$$

Using (13), (20) and (22), we get: 


$$
\left\{\begin{array}{l}
\dot{e_{1}}=I_{r d r e f}-\left(-b . I_{r d}+\omega_{r} . I_{r q}+a . V_{r d}\right) \\
\dot{e_{2}}=I_{r q r e f}-\left(-b . I_{r q}-\omega_{r} . I_{r d}-c . \phi s . \omega_{r}+a . V_{r q}\right)
\end{array}\right.
$$

In order to reduce the tracking error, we use a new Lyapunov candidate function, such that [5]:

$$
v_{1}=\frac{1}{2} e_{1}^{2}+\frac{1}{2} e_{2}^{2}
$$

Using (20) and (21), the derivative of the Lyapunov function becomes:

$$
\begin{gathered}
\dot{v}_{1}=e_{1} \cdot \dot{e}_{1}+e_{2} \cdot \dot{e}_{2} \\
\dot{v}_{1}=-k_{1} \cdot e_{1}^{2}-k_{2} \cdot e_{2}^{2}+e_{1} \cdot\left(k_{1} \cdot e_{1}+\dot{I_{r d r e f}}+b \cdot I_{r d}-\omega_{r} \cdot I_{r q}-a \cdot V_{r d}\right) \\
+e_{2} \cdot\left(k_{2} \cdot e_{2}+I_{r d r e f}+b \cdot I_{r q}+\omega_{r} \cdot I_{r d}+c . \phi s \cdot \omega_{r}-a \cdot V_{r q}\right)
\end{gathered}
$$

In order to ensure a good and stable tracking the derivatives of the Lyapunov function should be negative $\dot{v}_{1} \leq 0$ and $k_{1}$, $k_{2}$ positives parameters [13], [14]. From (23) the expressions of the control variables voltages $V_{r d}$ and $V_{r q}$ are given by:

$$
\left\{\begin{array}{l}
V_{r d r e f}=\frac{\dot{I_{r d r e f}}+b . I_{r d}-\omega_{r} \cdot I_{r q}+k_{1} \cdot e_{1}}{a} \\
V_{r q r e f}=\frac{\dot{I_{r q r e f}}+b . I_{r q}+\omega_{r} \cdot I_{r d}+c . \phi s . \omega_{r}+k_{2} \cdot e_{2}}{a}
\end{array}\right.
$$

\section{B. Control of the GSC}

In order to supply the rotor side converter and realize a robust variable speed control, we need to rectifier interfacing the grid, so the DC Bus voltage must be maintain to a constant value, the aim of the control of the GSC is to ensures a good regulation of the DC bus voltage $U_{d c}$ and have a unity power in the grid side [4].

The expression of the electrical currents of the Filter becomes:

$$
\left\{\begin{array}{l}
\frac{d I_{f d}}{d t}=\frac{1}{L_{f}}\left(-V_{f d}-R_{f} \cdot I_{f d}+\omega_{s} \cdot I_{f q}\right) \\
\frac{d I_{f q}}{d t}=\frac{1}{L_{f}}\left(V_{s q}-V_{f q}-R_{f} \cdot I_{f q}-\omega_{s} \cdot I_{f d}\right)
\end{array}\right.
$$

As shown in (14) the active power $P_{f}$ can be controlled by $I_{f q}$ and the reactive power $Q_{f}$ can be controlled by $I_{f d}$.
The currents tracking errors $e_{3}$ and $e_{4}$ are defined by:

$$
\left\{\begin{array}{l}
e_{3}=I_{f d r e f}-I_{f d} \\
e_{4}=I_{f q r e f}-I_{f q}
\end{array}\right.
$$

The derivatives of the errors give:

$$
\left\{\begin{array}{l}
\dot{e_{3}}=I_{f d r e f}-\dot{\bullet} \\
\dot{e_{4}}=I_{f q r e f}-\dot{I}_{f q}
\end{array}\right.
$$

Using (25) and (27) the derivatives of the errors variables becomes

$$
\left\{\begin{array}{l}
\dot{e_{3}}=I_{f d r e f}-\left(-\frac{V_{f d}}{L_{f}}-\frac{R_{f} \cdot I_{f d}}{L_{f}}+\omega_{s} \cdot I_{f q}\right) \\
\dot{e_{4}}=I_{f q r e f}-\left(\frac{V_{s q}}{L_{f}}-\frac{V_{f q}}{L_{f}}-\frac{R_{f} \cdot I_{f q}}{L_{f}}+\omega_{s} \cdot I_{f d}\right)
\end{array}\right.
$$

To reduce the tracking error, we chose the following Lyapunov function [13]:

$$
v_{2}=\frac{1}{2} e_{3}^{2}+\frac{1}{2} e_{4}^{2}
$$

The derivative of the Lyapunov function is given by

$$
\dot{v_{2}}=e_{3} \cdot \dot{e}_{3}+e_{4} \cdot \dot{e}_{4}
$$

Replacing the derivative of the errors by using (28) and (30), the expression of the derivative of the Lyapunov function becomes:

$$
\begin{aligned}
& \dot{v_{2}}=-k_{3} \cdot e_{3}^{2}-k_{4} \cdot e_{4}^{2}+e_{3} \cdot\left(k_{3} \cdot e_{3}+\dot{I_{f d r e f}}-\left(-\frac{V_{f d}}{L_{f}}-\frac{R_{f} \cdot I_{f d}}{L_{f}}+\omega_{s} \cdot I_{f q}\right)\right)+ \\
& e_{4} \cdot\left(k_{4} \cdot e_{4}+\stackrel{\bullet}{I_{f q r e f}}-\left(\frac{V_{s q}}{L_{f}}-\frac{V_{f q}}{L_{f}}-\frac{R_{f} \cdot I_{f q}}{L_{f}}+\omega_{s} \cdot I_{f d}\right)\right)
\end{aligned}
$$

In order to ensure a good and stable control the derivatives of the Lyapunov function should be negative so we chose $k_{3}$ and $k_{4}$ positives [13]. The expressions of the control variable $V_{f d}$ and $V_{f q}$ to impose on the GSC are expressed as following equations: 


$$
\left\{\begin{array}{l}
V_{f d}=-L_{f}\left(\dot{I_{f d r e f}}+\frac{R_{f}}{L_{f}} \cdot I_{f d}-\omega_{s} \cdot I_{f q}+k_{3} \cdot e_{3}\right) \\
V_{f q}=-L_{f}\left(\dot{\bullet} \cdot \dot{I_{f q r e f}}+\frac{R_{f}}{L_{f}} \cdot I_{f q}+\omega_{s} \cdot I_{f d}-\frac{V_{s q}}{L_{f}}+k_{4} \cdot e_{4}\right)
\end{array}\right.
$$

That ensure $\dot{v_{2}} \leq 0$. The performance and the stability the of the system are giving by a good choice of $k_{3}$ and $k_{4}$.

\section{Dc Bus Voltage Control:}

In power terms and by neglecting the converter losses, the DC bus equation can be written as following expressions [15]:

$$
\left\{\begin{array}{l}
W_{d c}=\int P_{d c} \cdot \mathrm{dt}=\frac{1}{2} \cdot C \cdot U_{d c}{ }^{2} \\
\frac{d U_{d c}^{2}}{d t}=\frac{2}{C} \cdot\left(P_{f}-P_{r}\right)
\end{array}\right.
$$

where $W_{d c}$ and $P_{d c}$ are the energy and the power in the DCBus Capacitor.

$$
\left\{\begin{array}{l}
P_{f}=P_{d c}+P_{r} \\
P_{d c}=U_{d c} \cdot \mathrm{I}_{d c}
\end{array}\right.
$$

According (34) it is possible to control the power $P_{d c}$ in the DC-Bus By adjusting the power $P_{f}$ to control the Dc voltage [13]. We can used PI controller (Fig. 3).

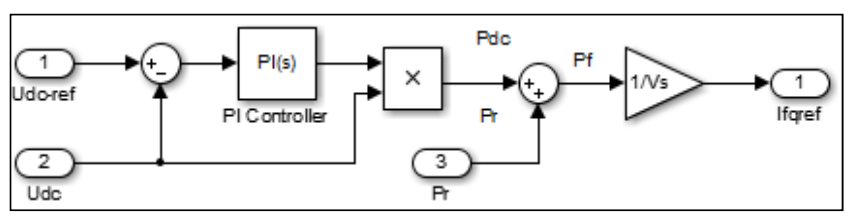

Fig. 3 Control loop of DC bus Voltage Block in SIMULINK

\section{SimUlation RESUlTS}

The global model of the wind system using a DFIG was simulated in MATLAB/SIMULINK. The parameters of the system are given in the appendix. To improve the robustness and the performance of the Backstepping controller we apply a random wind profile which varies between $7 \mathrm{~m} / \mathrm{s}$ and $11 \mathrm{~m} / \mathrm{s}$ presented in Fig. 4.

The profile of the mechanical rotor speed of the machine which is driven in rotation by wind is presented in Fig. 5. Mechanical rotor speed varies in the same shape as the wind speed, in order to extract the maximum of the electrical power for different value of wind speed [4], it varies between 1000 rpm and $1600 \mathrm{rpm}$, the parameters of the DFIG are given in the appendix.

Fig. 6 shows that the rotor currents Irq which controls the electromagnetic torque of the DFIG perfectly follows it reference. From Fig. 7 it can be seen that the stator active power is negative $P_{s}<0$ which means that the network is a receiver of the energy produced by the generator. Ps varies between $-100 \mathrm{KW}$ and $-600 \mathrm{KW}$, against this variation the power coefficient $C p$ kept at its maximum value $C p=0.48$ (From Fig. 8) which confirm the robustness of the MPPT controller.

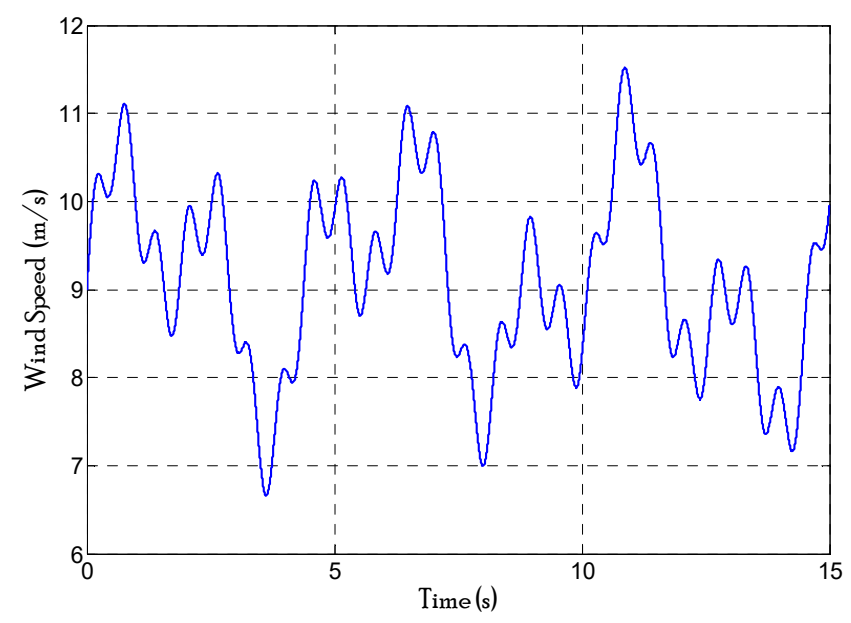

Fig. 4 Wind Speed Profile

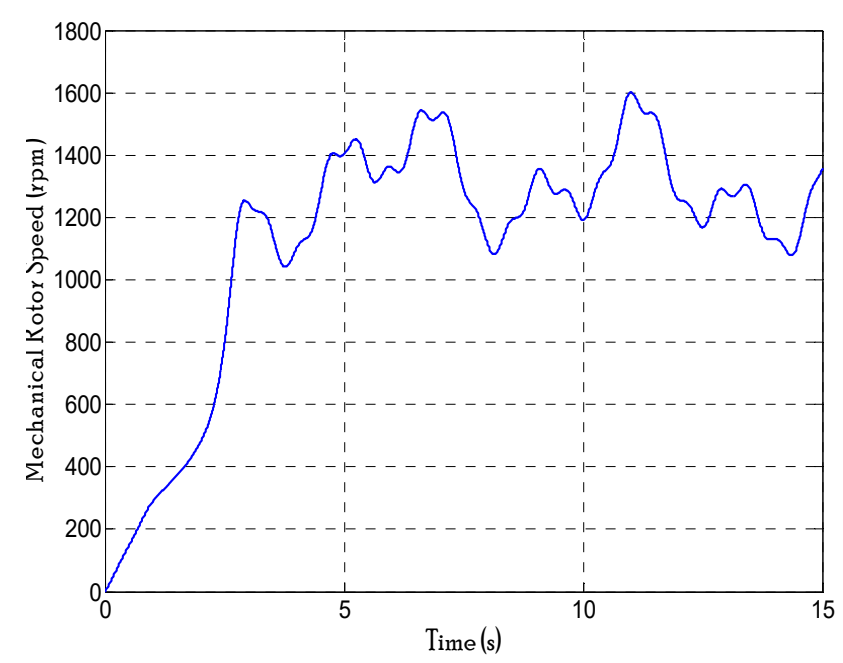

Fig. 5 The Mechanical Rotor Speed (rpm)

The DC bus voltage reference is kept at a constant value $U_{d c-r e f}=900 \mathrm{~V}$, from Fig. 9 we can see that DC voltage $U_{d c}$ follows this constant; Fig. 10 presents active power grid side. Scanning the simulation results, it can be concluded that MPPT control and Backstepping approach are efficient and robust. 


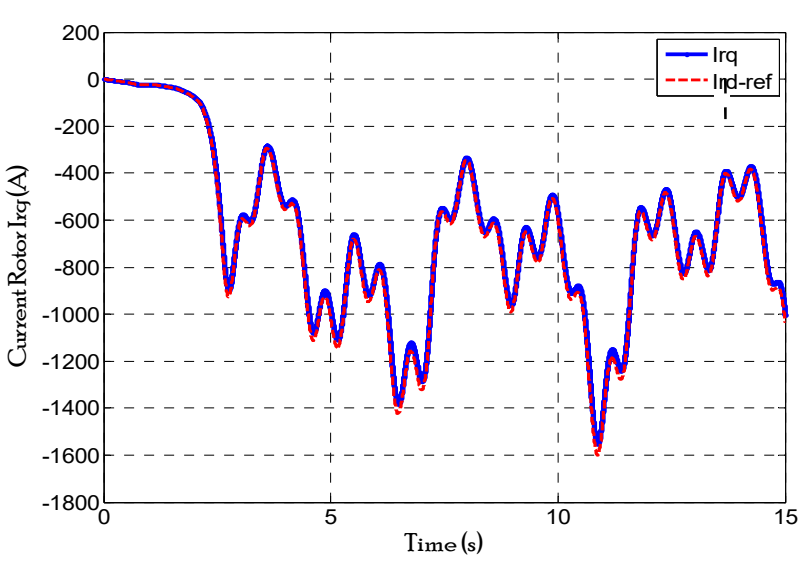

Fig. 6 Current rotor Irq and its reference

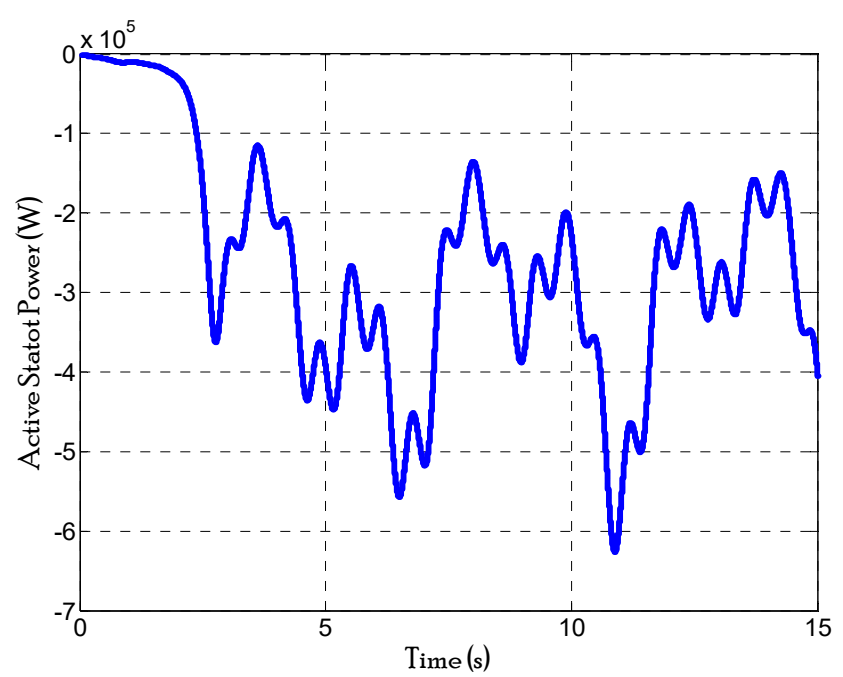

Fig. 7 Active Stator Power (W)

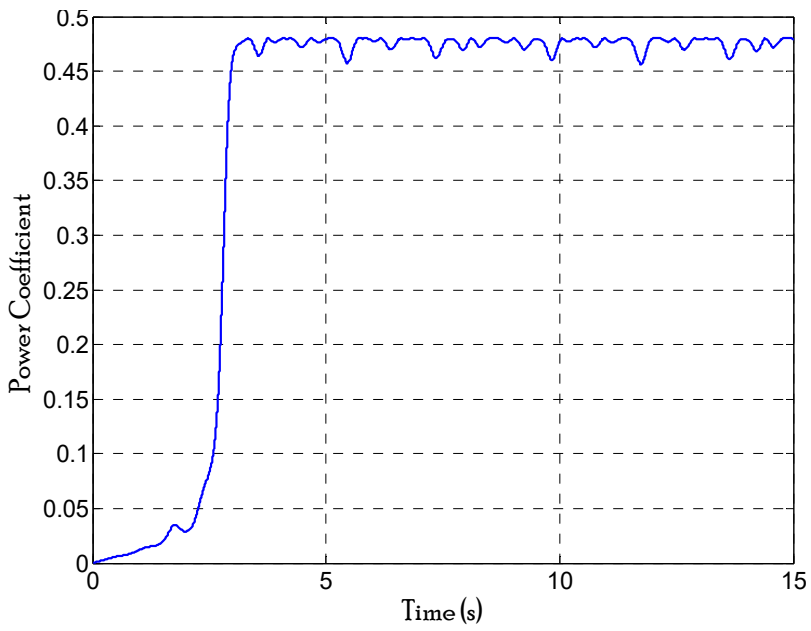

Fig. 8 Power Coefficient $\mathrm{Cp}$

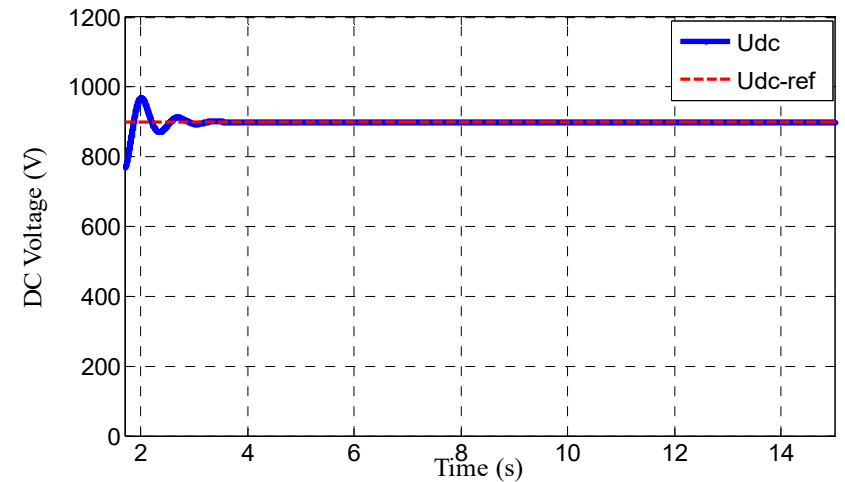

Fig. 9 DC Voltage and its Reference

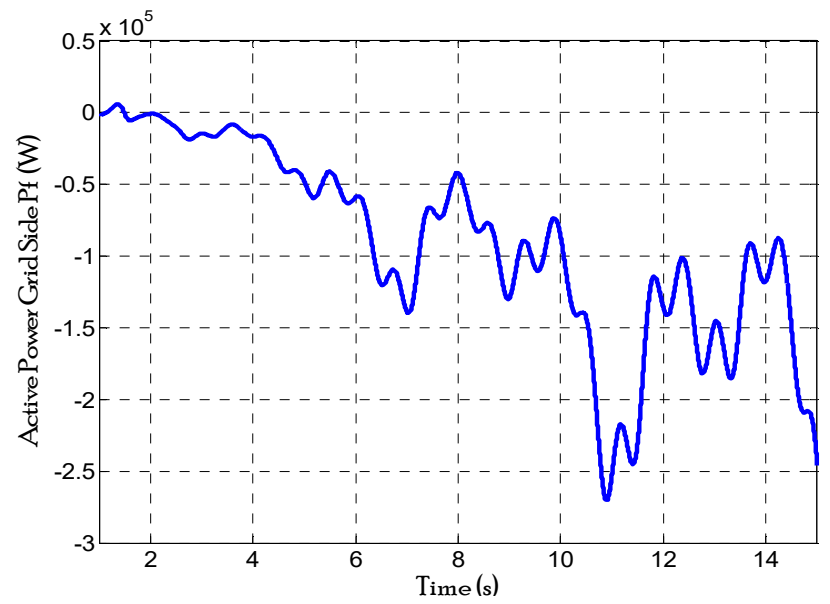

Fig. 10 Active Power Grid Side (W)

\section{CONCLUSION}

The work presented in this paper was devoted to control of a DFIG applied in a wind energy conversion system, after modeling the wind turbine and the DFIG in the d-q axis, we have established a vector control of the machine based in the flux oriented in order to relies a decoupling between direct and quadrature currents, then we have applied the Nonlinear Backstepping approach to control the two converter the RSC and the GSC in order to maximize capture wind energy. The simulation results show that the Nonlinear Backstepping controller is efficient and is a good approach for controlling the machine, it make possible to have an optimal operation of the electrical generation system and ensure some important strength and stability against variable wind speed.

\section{APPENDIX}

TABLE I

PARAMETER OF DFIG

\begin{tabular}{cc}
\hline \hline Denotation & Numerical value of parameter \\
\hline Rated Power & $P=660 \mathrm{KW}$ \\
Nominal Frequency & $f=50 \mathrm{~Hz}$ \\
Number of pole pair & $p=2$ \\
Stator Resistance & $R_{s}=0.0146 \Omega$ \\
Rotor Resistance & $R_{r}=0.0238 \Omega$ \\
Stator Inductance & $L_{s}=0.0306 \mathrm{H}$ \\
Rotor Inductance & $L_{r}=0.0303 \mathrm{H}$ \\
Mutual Inductance & $L_{m}=0.0299 \mathrm{H}$ \\
\hline \hline
\end{tabular}


TABLE II

PARAMETER OF WIND TURBINE

\begin{tabular}{cc}
\hline \hline Denotation & Numerical value of parameter \\
\hline Radius of the Turbine & $R=21.165 \mathrm{~m}$ \\
Gain Multiplier & $G=39$ \\
Inertia Total Moment & $J=28 \mathrm{~kg} \cdot \mathrm{m}^{2}$ \\
Coefficient of Viscous Friction & $C_{f}=0.01 \mathrm{~m} / \mathrm{s}$ \\
Optimal Tip Speed Ratio & $\lambda_{o p t}=8.1$ \\
Maximal Power Coefficient: & $C_{p \max }=0.48$ \\
\hline \hline
\end{tabular}

TABLE III

PARAMETERS OF FILTER RL \& DC-BUS

\begin{tabular}{cc}
\hline Symbol & Value \\
\hline$L f$ & $3 \mathrm{mH}$ \\
$R f$ & $0.4 \Omega$ \\
$C$ & $2.2 \mathrm{mF}$ \\
\hline
\end{tabular}

\section{REFERENCES}

[1] A. Boualouch, A. Frigui, T. Nasser, A. Essadki, A. Boukhriss, "Control of a Doubly-Fed Induction Generator for Wind Energy Conversion Systems by RST Controller", International Journal of Emerging Technology and Advanced Engineering, Vol. 4, pp. 93-99, August 2014.

[2] B. Fredo,L. Marco, and M. Ke,Power Electronics Converters for Wind turbine Systems, IEEE Transaction on industry applications, vol. 48, No. 2, March/April 2012

[3] R. Chakib, A. Essadki, M. Cherkaoui, "Modeling and Control of a Wind System based on a DFIG by Active Disturbance rejection control", International Review on Modeling and Simulations, Vol. 7, pp. 626-637, August 2014.

[4] R. Chakib, A. Essadki, M. Cherkaoui, "Active Disturbance Rejection Control for Wind System Based On a DFIG", International Journal of Electrical Computer Energetic Electronic and Communication Engineering, Vol. 8, pp. 1306-1315, 2014.

[5] M. Rachidi, B. B. Idrissi, "Robust Nonlinear Backstepping Control Design for Doubly Fed Induction Machine in Wind Power Generation", International Journal of Research in Engineering \& Advanced Technology, Vol. 3, pp. 137-145, Feb-Mar 2015.

[6] M. Nadour, A. Essadki, T. Nasser. "Comparative Analysis between PI \& Backstepping Control Strategies of DFIG Driven by Wind Turbine". International Journal of Renewable Energy Research, Vol. 7, No 3, pp 1307-1316, September 2017.

[7] D. R. Rush and G. W. David, "Nonlinear Power Flow Control Design", Springer, New York, NY, USA, 2011.

[8] B. Bossoufi, M. Karim, A. Lagrioui, \& all, "Observer backstepping control of DFIG-Generators for wind turbines variable-speed: FPGAbased implementation". Renewable Energy, Elsevier, Vol. 81, pp. $903-$ 917, 2015.

[9] C. Z. El Archi, T. Nasser, A. Essadki, "Power Control of DFIG Based Wind System: Comparison between Active Disturbance Rejection Controller and PI Controller", ARPN Journal of Engineering and Applied Sciences, Vol. 11, pp. 13980-13989, December 2016.

[10] A. Boualouch, A. Essadki, T. Nasser, A. Boukhriss, A. Frigui, "Power Control of DFIG in WECS Using Backstipping and Sliding Mode Controller", International Journal of Electrical Computer Energetic Electronic and Communication Engineering, Vol. 9, pp. 612-618, 2015.

[11] K. Ghedamsi, E.M. Berkouk, "Control of Wind Generator Associated to a Flywheel Energy Storage System", Renewable Energy, Elsevier, Vol. 33, pp. 2145-2156, 2008.

[12] F. Ikhouane, M. Krstc, "Robustness of the Tuning Functions Adaptive Backstepping Design for Linear Systems", IEEE Transl. Automat. Contr., Vol. 43, pp. 431-437, 1998

[13] M. El Azzaoui, H. Mahmoudi, K. Boudaraia, "Backstepping Control of wind and photovoltaic hybrid Renewable Energy System". International Journal of Power Electronics and Drive Systems, Vol.7, pp. 677-686, September 2016.

[14] S. Mensou, A. Essadki, T. Nasser, B. B. Idrissi, "An Efficient Nonlinear Backstepping Controller Approach of a Wind Power Generation System Based on a DFIG". International Journal of Renewable Energy Research, Vol.7, No 4, pp. 1520-1528, December 2017.

[15] L. Jerbi, L. Krichen, A. Ouali, "A fuzzy logic supervisor for active and reactive power control of a variable speed wind energy conversion system associated to a flywheel storage system". Electric power systems research, Elsevier, Vol. 79(6), pp 919-925, 2009. 